\title{
Recurrent aortopulmonary artery fistula
}

\author{
BRIAN F. BUXTON ${ }^{1}$ and DENTONA. COOLEY \\ Division of Surgery of the Texas Heart Institute of St. Luke's Episcopal and Texas Children's Hospitals, \\ Texas Medical Center, Houston, Texas, U.S.A.
}

\begin{abstract}
Buxton, B. F., and Cooley, D. A. (1973). Thorax, 28, 521-525. Recurrent aortopulmonary artery fistula. The case report is presented of a patient who underwent successful repair of a recurrent fistula between the aorta and the pulmonary artery secondary to an atherosclerotic aneurysm of the ascending thoracic aorta. The fistula was situated between the proximal part of the ascending aorta and the proximal part of the main pulmonary artery and was associated with aortic incompetence together with pulmonary valvular stenosis and incompetence. The repair involved prosthetic replacement of both the pulmonary and aortic valves, the main pulmonary artery, and the ascending thoracic aorta.
\end{abstract}

An aortopulmonary artery fistula is a rare complication of an atherosclerotic aneurysm of the ascending thoracic aorta (Nicholson, 1943). A fistula between the thoracic aorta and the pulmonary artery has also been reported following rupture of a dissecting thoracic aneurysm and trauma (Ward and Kalbfleisch, 1968 ; Bory et al., 1970 ; Zajtchuk, Resnekov, Ranniger, and Gonzalez-Lavin, 1971). The case report is presented of a patient with a recurrent aortopulmonary artery fistula resulting from rupture of an aneurysm of the ascending thoracic aorta. Corrective treatment included prosthetic replacement of the ascending aorta, aortic valve, pulmonary artery, and pulmonary valve.

\section{CASE REPORT}

A 52-year-old man was asymptomatic until January 1968 when he developed myalgia, fever, chills, and dyspnoea lasting for approximately one week. At that time a cardiac murmur was heard and a diagnosis of subacute bacterial endocarditis was made. On admission to hospital his temperature was $101^{\circ} \mathrm{F}\left(38^{\circ} \mathrm{C}\right)$ and his blood pressure $240 / 100 \mathrm{mmHg}$. A continuous machinery-like murmur was heard over the precordium. The patient was treated for subacute bacterial endocarditis although blood cultures were negative. Cardiac catheterization was performed the following month. The pressures and saturations are summarized in the Table. Injection of radiopaque dye into the proximal aorta demonstrated a communication between the aorta and the pulmonary artery distal to the origin of the left coronary artery.

1 Reprint requests should be addressed to : Mr. Brian Buxton, Department of Surgery, Royal Melbourne Hospital, Victoria, Australia 3050
T A B L E

SUMMARY OF PREOPERATIVE CARDIAC CATHETERIZATION DATA

\begin{tabular}{|c|c|c|c|c|c|}
\hline & & \multicolumn{2}{|c|}{ February 1968} & \multicolumn{2}{|c|}{ April 1972} \\
\hline & & $\begin{array}{l}\text { Pressure } \\
\text { (mmHg) }\end{array}$ & $\underset{\%}{\mathrm{O}_{2}}$ & $\begin{array}{c}\text { Pressure } \\
(\mathrm{mmHg})\end{array}$ & $\underset{\substack{\mathrm{O}_{\mathbf{2}} \\
\text { Saturation }}}{\mathrm{O}_{0}}$ \\
\hline $\begin{array}{l}\text { Right atrium } \\
\text { Right ventricle } \\
\text { Pulmonary artery } \\
\text { Pulmonary wedge } \\
\text { Aorta } \\
\text { Left ventricle } \\
\text { Left atrium }\end{array}$ & $\begin{array}{l}\cdots \\
\cdots \\
\cdots \\
\cdots\end{array}$ & $\begin{array}{c}8 \\
58 / 15 \\
58 / 13 \\
21 \\
160 / 60\end{array}$ & $\begin{array}{l}58 \\
65 \\
76\end{array}$ & $\begin{array}{c}18 \\
120 / 10 \\
40 / 20 \\
17 \\
160 / 60 \\
200 / 20\end{array}$ & $\begin{array}{l}61 \\
63 \\
84 \\
95 \\
98\end{array}$ \\
\hline
\end{tabular}

Surgical correction of the lesion was attempted on 23 February 1968. This operation consisted of dividing the fistula, thus detaching the aorta from the pulmonary artery and oversewing the defect in both aorta and pulmonary artery. Three days after surgery the patient developed a murmur similar to that which existed before surgery. He also experienced a transient left hemiparesis which lasted for two days. Cardiac catheterization was repeated on 16 April 1968 and again showed a communication between the aorta and the pulmonary artery. An occluded left subclavian artery and a left subclavian steal were also noted. Despite these abnormal findings he was relatively asymptomatic and returned to light work.

Four months before admission on 19 April 1972 the patient developed dyspnoea and bilateral ankle oedema. He could not walk more than 100 yards $(90 \mathrm{~m})$ without severe shortness of breath. Review of serial chest radiographs during the six months prior to this admission revealed an increase in heart size even though, over this period, he was being maintained on $0.05 \mathrm{mg}$ digitoxin, $50 \mathrm{mg}$ frusemide (Lasix), and $60 \mathrm{mEq}$ of potassium chloride daily. On examination he was in no distress, his jugular venous pressure 
was slightly elevated, and a systolic bruit could be heard over both carotid arteries. The blood pressure in the right arm was $230 / 130 \mathrm{mmHg}$ and pulse rate 80 beats/minute. A systolic thrill was palpable along the left sternal border, maximal in the third intercostal space. The heart size was normal on percussion. A rough grade V/VI systolic murmur was audible over the precordium radiating to the neck and abdomen. This murmur was best heard in the third left intercostal space near the sternum. Also a grade I/VI diastolic murmur was heard throughout the precordium. The remainder of the physical examination was within normal limits except for mild oedema of both ankles. A presumptive diagnos:s was made of an ascending thoracic aortic aneurysm with a recurrent aortopulmonary artery fistula.

Left and right heart catheterization on 20 April 1972 confirmed the presence of a recurrent aortopulmonary artery fistula as well as an aneurysm of the ascending thoracic aorta. In addition he was found to have significant pulmonary valvular stenosis. The pressures and oxygen saturations are shown in the Table. The left-to-right shunt was estimated to be 2.6 to 1 . An electrocardiogram revealed left ventricular hypertrophy and an anterolateral subendocardial injury. The haemoglobin was $16.4 \mathrm{~g} \%$ and the serum bilirubin $3.5 \mathrm{mg} \%$.

OPERATION Surgical correction of the aortopulmonary artery fistula was carried out on 24 April 1972. The sternotomy was reopened, the superior and inferior venae cavae were cannulated for venous outflow and the distal ascending aorta for arterial return. The patient was placed on cardiopulmonary bypass using a disposable bubble oxygenator and cooled to $30^{\circ} \mathrm{C}$. The distal ascending aorta was clamped to produce ischaemic cardiac arrest and a vent was made in the left atrium via the right superior pulmonary vein.

The aneurysm of the ascending aorta extended from the root of the aorta almost to the arch, measuring $7 \mathrm{~cm}$ at its maximal diameter. The fistula was situated between the ascending aorta above the junction of left and right coronary cusps and the main pulmonary artery above the commissure between the posterior and medial valve leaflets (Fig. 1). The aortic annulus was dilated and the aortic valve was incompetent. The main pulmonary artery was also dilated, the fistula entering immediately above the pulmonary valve which was not only stenotic but incompetent.

The aneurysm of the ascending aorta was excised
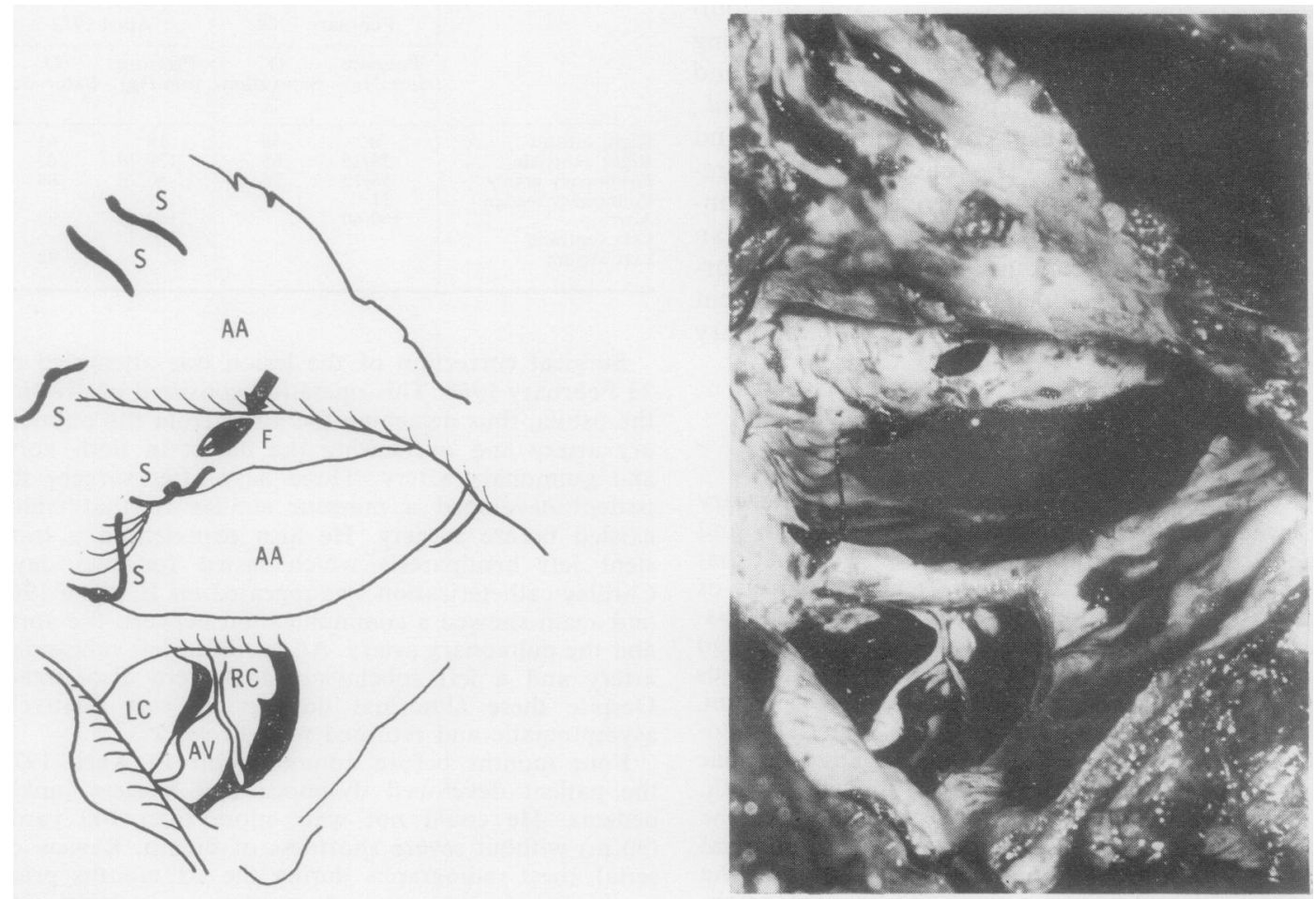

FIG. 1. Inside of ascending aorta showing aortic valve $(A V)$, left coronary cusp $(L C)$, right coronary cusp (RC), the aortopulmonary fistula $(F)$, ascending aortic aneurysm $(A A)$, and the old sutures $(S)$. 

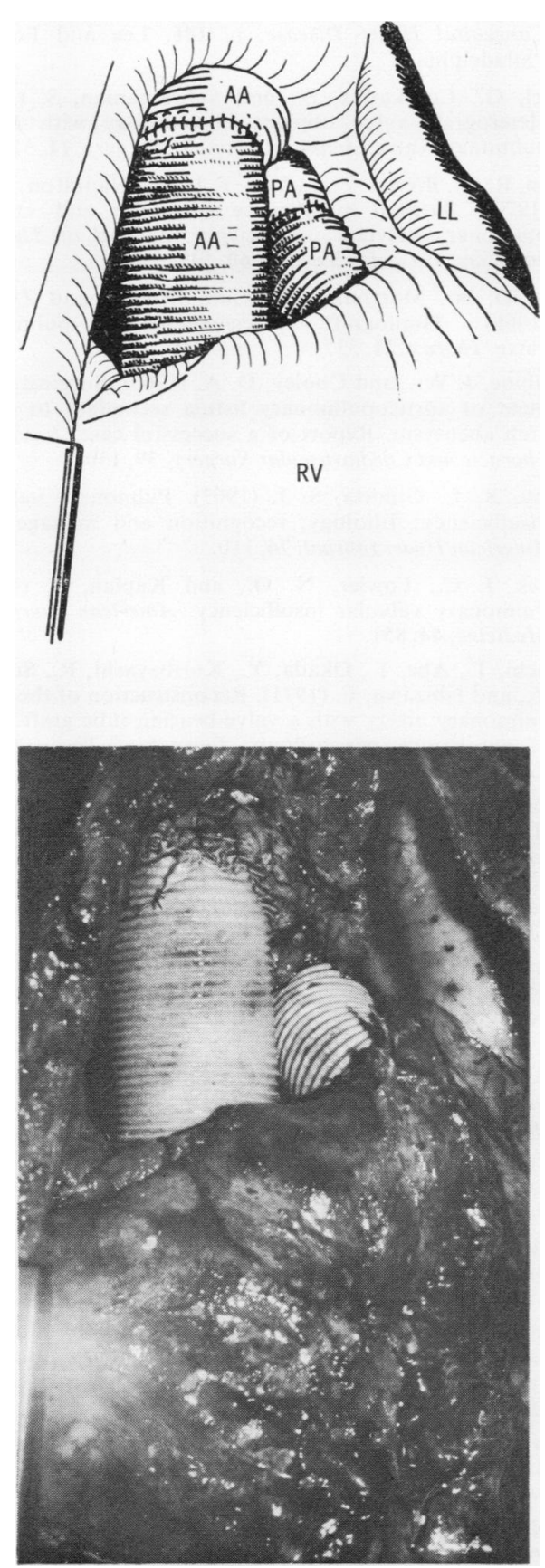

FIG. 2. The reconstructed pulmonary artery $(P A)$ and ascending aorta $(A A)$. The left ling (LL) is shown on the right. together with the leaflets of the aortic valve, leaving a cuff of aortic wall distal to the coronary orifices. The pulmonary artery was opened and the proximal portion excised with the remnants of the pulmonary valve. A $25 \mathrm{~mm}$ Björk-Shiley Pyrolite disc aortic valve prosthesis was inserted into the pulmonary annulus. A $26 \mathrm{~mm}$ woven Dacron tube was sutured to the pulmonary valve prosthesis proximally and to the pulmonary artery distally. A further Björk-Shiley aortic valve prosthesis $(23 \mathrm{~mm})$ was then sutured into the aortic annulus and the ascending aorta was reconstructed using a woven $30 \mathrm{~mm}$ Dacron tube (Fig. 2). Air was evacuated from the heart which required a single countershock to restore normal sinus rhythm. The total bypass time was 113 minutes and the period of ischaemic cardiac arrest was 103 minutes. The estimated blood loss was $1,500 \mathrm{ml}$; no blood was administered during the procedure.

After operation the patient remained well although his jugular venous pressure was elevated and a grade II/VI systolic bruit was heard over the pulmonary area. The serum bilirubin increased to $9.6 \mathrm{mg} \%$ on the third day following operation when his haemoglobin was $10.5 \mathrm{~g} \%$. By the ninth day the serum bilirubin had returned to the preoperative level of $3.5 \mathrm{mg} \%$. Warfarin sodium (Coumadin) was started on the third postoperative day, and the prothrombin time was maintained at approximately $30 \%$ of normal. The patient was discharged from hospital on the twelfth day after surgery, at which time he was ambulatory. One month after surgery he was able to walk a quarter of a mile without difficulty.

\section{DISCUSSION}

The repair of a recurrent fistula between the aorta and the pulmonary artery following rupture of an atherosclerotic aneurysm presents a challenging surgical problem, particularly when the fistula is complicated by lesions in the aortic and pulmonary valves. The repair of such a lesion has not been reported, so far as we are aware, although an uncomplicated aortopulmonary artery fistula has been corrected successfully (Giacobine and Cooley, 1960).

Replacement of an ascending thoracic aortic aneurysm associated with an incompetent aortic valve by a Dacron tube graft and a prosthetic aortic valve is an accepted form of treatment (Cooley et al., 1966 ; Cooley, Bloodwell, Hallman, and Jacobey, 1967). However, the technique of reconstruction of the pulmonary artery and the necessity for repair of a damaged pulmonary valve are matters of dispute. Numerous materials have been used for reconstruction of the pulmonary artery. Pericardium was introduced by Rastelli, Ongley, Davis, and Kirklin (1965), while fascia lata has been advocated by Ionescu and Deac (1970) and Lincoln, Geens, Ross, and Ionescu 
(1971). Both of these materials undergo degeneration (Björk and Björk, 1967; Ross and Somerville, 1971 ; Rosenthal, Gross, and Pasternac, 1972 ; Ionescu, Macartney, Wooler, and Gerbode, 1972; Imamura, Konno, Arai, and Sakakibara, 1972). As a result Dacron is now preferred by some surgeons (Björk and Björk, 1967).

The necessity for replacing the pulmonary valve is even more controversial. While isolated pulmonary valvular insufficiency is well tolerated by most patients (Laneve, Uesu, and Taguchi, 1962; Hamby and Gulotta, 1967 ; Holmes, Fowler, and Kaplan, 1968), evidence is accumulating which suggests that pulmonary valvular insufficiency is not always benign, particularly in patients with pulmonary vascular disease (Smith, DuShane, and Edwards, 1959 ; Campbell, 1959 ; Ellison, Brown, Yeh, and Hamilton, 1970 ; Verginelli et al., 1971). Autologous, homologous, and heterologous substitutes have been used to reconstruct the pulmonary valve in an attempt to overcome the longterm effects of pulmonary valvular insufficiency, but the results are uncertain (Ross and Somerville, 1966 and 1971 ; Fuller, Marchand, Zion, and Zwi, 1966 ; Marchand, 1967 ; Weldon, Rowe, and Gott, 1968; McGoon, Rastelli, and Ongley, 1968; Wallace et al., 1969; Horiuchi et al., 1971; Cornel, Colokathis, and Subramanian, 1971; Verginelli et al., 1971 ; Lincoln et al., 1971 ; Imamura et al., 1972). Although our earlier experience with the use of a prosthetic pulmonary valve in patients with congenital heart disease was disappointing, the successful use of a prosthesis for the pulmonary valve in this patient raises the possibility that this might be a practical alternative to the use of biological materials for the pulmonary valve in an adult (Cooley and Hallman, 1966).

\section{REFERENCES}

Björk, V. O., and Björk, L. (1967). Pericardial outflow prosthesis of the right ventricle. Scandinavian Journal of Thoracic and Cardiovascular Surgery, 1, 47.

Bory, M., Donnarel, G., Djiane, P., Dor, V., and Serradimigni, A. (1970). Dissection aortique rompue dans l'artère pulmonaire chez un malade atteint d'hypercholestérolémie familiale. Archives de Maladies du Coeur et des Vaisseaux, 63, 1197.

Campbell, M. (1959). Valvulotomy as a curative operation for simple pulmonary stenosis. British Heart Journal, 21, 415.

Cooley, D. A., Bloodwell, R. D., Beall, A. C., Hallman, G. L., and De Bakey, M. E. (1966). Surgical management of aneurysms of the ascending aorta. Including those associated with aortic valvular incompetence. Surgical Clinics of North America, 46, 1033.

—_ _- Hallman, G. L., and Jacobey, J. A. (1967). Aneurysm of the ascending aorta complicated by aortic valve incompetence. Surgical treatment. Journal of Cardiovascular Surgery, $8,1$.
Congenital Heart Disease, p. 185. Lea and Febiger, Philadelphia.

Cornel, G., Colokathis, B., and Subramanian, S. (1971). Heterograft valve implant in tetralogy with absent pulmonary valve. Annals of Thoracic Surgery, 11, 51 .

Ellison, R. G., Brown, W. J., Yeh, T. J., and Hamilton, W. F. (1970). Surgical significance of acute and chronic pulmonary valvular insufficiency. Journal of Thoracic and Cardiovascular Surgery, 60, 549.

Fuller, D. N., Marchand, P., Zion, M. M., and Zwi, S. (1966). Homograft replacement of the pulmonary valve. Thorax, $21,337$.

Giacobine, J. W., and Cooley, D. A. (1960). Surgical treatment of aorticopulmonary fistula secondary to aortic arch aneurysm. Report of a successful case. Journal of Thoracic and Cardiovascular Surgery, 39, 130.

Hamby, R. I., Gulotta, S. J. (1967). Pulmonary valvular insufficiency: Etiology, recognition and management. American Heart Journal, 74, 110.

Holmes, J. C., Fowler, N. O., and Kaplan, S. (1968). Pulmonary valvular insufficiency. American Journal of Medicine, 44, 851 .

Horiuchi, T., Abe, T., Okada, Y., Kuribayashi, R., Suzuki, Y., and Ishizawa, E. (1971). Reconstruction of the main pulmonary artery with a valve-bearing tube graft made of autologous pericardium. Journal of Thoracic and Cardiovascular Surgery, 62, 793.

Imamura, E. S., Konno, S., Arai, T., and Sakakibara, S. (1972). Composite graft of heterologous pulmonary valve and prosthetic tube for the reconstruction of right ventricular outflow tract. Clinical application in four patients. Journal of Thoracic and Cardiovascular Surgery, 63, 747.

Ionescu, M. I., and Deac, R. C. (1970). Fascia lata composite graft for right ventricular outflow tract and pulmonary artery reconstruction. Thorax, 25, 427.

- Macartney, F. J., Wooler, G. H., and Gerbode, F. (1972). Reconstruction of the right ventricular outlet with fascia lata composite graft. Journal of Thoracic and Cardiovascular Surgery, 63, 60.

Laneve, S. A., Uesu, C. T., and Taguchi, J. T. (1962). Isolated pulmonic valvular regurgitation. American Journal of Medical Science, 244, 446.

Lincoln, C., Geens, M., Ross, D., and Ionescu, M. (1971). Replacement of pulmonary valve and pulmonary artery with fascia lata (abstract). British Heart Journal, 33, 146.

Marchand, P. (1967). The use of a cusp-bearing homograft patch to the outflow tract and pulmonary artery in Fallot's tetralogy and pulmonary valvular stenosis. Thorax, 22, 497.

McGoon, D. C., Rastelli, G. C., and Ongley, P. A. (1968). An operation for the correction of truncus arteriosus. Journal of the American Medical Association, 205, 69.

Nicholson, R. E. (1943). Syndrome of rupture of aortic aneurysm into the pulmonary artery. Review of the literature with report of 2 cases. Annals of Internal Medicine, 19, 286.

Rastelli, G. C., Ongley, P. A., Davis, G. D., and Kirklin, J. W. (1965). Surgical repair for pulmonary valve atresia with coronary-pulmonary artery fistula. Report of a case. Mayo Clinic Proceedings, 40, 521. 
Rosenthal, A., Gross, R. E., and Pasternac, A. (1972). Aneurysms of right ventricular outflow patches. Journal of Thoracic and Cardiovascular Surgery, 63, 735.

Ross, D. N., and Somerville, J. (1966). Correction of pulmonary atresia with a homograft aortic valve. Lancet, 2 , 1446.

- (1971). Fascia-lata reconstruction of the right ventricular outflow tract. Lancet, $1,941$.

Smith, R. D., DuShane, J. W., and Edwards, J. E. (1959). Congenital insufficiency of the pulmonary valve including a case of fetal cardiac failure. Circulation, 20, 554.

Verginelli, G., Martin, J., Marcial, M. B., Macruz, R., and Zerbini, E. J. (1971). Pulmonary valve insufficiency in a case of tetralogy of Fallot after Brock's operation. Correction by heterologous aortic graft. Journal of Thoracic and Cardiovascular Surgery, 62, 436.
Wallace, R. B., Rastelli, G. C., Ongley, P. A., Titus, J. L., and McGoon, D. (1969). Complete repair of truncus arteriosus defects. Journal of Thoracic and Cardiovascular Surgery, 57, 95.

Ward, R. W., and Kalbfleisch, J. M. (1968). Rupture of aortic aneurysm into the pulmonary artery. Southern Medical Journal, 61, 408.

Weldon, C. S., Rowe, R. D., and Gott, V. L. (1968). Clinical experience with the use of aortic valve homografts for reconstruction of the pulmonary artery, pulmonary valve, and outflow portion of the right ventricle. Circulation, 37 and 38 Suppl. II, p. 51.

Zajtchuk, R., Resnekov, L., Ranniger, K., and GonzalezLavin, L. (1971). Traumatic aorta to pulmonary a rtery fistula. Thorax, 26, 219. 